\title{
Cinephiles! as Post-Zine: Cinephilia in the Age of Digital Networks
}

Adrian D. Mendizabal

In Janet Staiger's (1985) essay Politics of Film Canons, I encountered the strange polysemic word "selection," which Staiger described as a "politics of inclusion and exclusion" (p. 8). Staiger opened her essay on film canons with a reinvigorated inquiry on the "politics of choice" associated with dynamic assemblage of audio-visual culture.

Staiger (1985) asserted that the films part of the canon were not only fixtures in bibliographic institutions, but also constitute a binding agreement among a group of individuals. Essentially, Staiger argued that an act of selection was entirely a means to achieve "uniformity...suppressing optional value systems" (p. 11) in order to create a consensus that awaits the collapse of the "other" and enunciates the arrival of the "same." Staiger sees the activity of selection as a reaffirming act of the hegemonic order, indeed "a politics of power."

Staiger (1985) described a lens through which to look at the network of power that constitutes cinephilia in the digital era. Staiger's elaboration on the politics of film canons also implicitly highlighted the positionality of choice within the capillaries of power relations, and insisted that film canons arose from what she calls a hegemonic mode of consensus building. Indeed, web cinephilia is not entirely ordered by a purely human agency but also by various layers of control. The technological apparatuses of digital communication i.e. the computer, the algorithm, the hardware-software material interfaces participate in the amplification of the hegemonic ideology 
by serving as a control centre for institutions of power. These apparatuses intervene in the process of choosing, hierarchizing, and disseminating information within the digital network. Is hegemonic consensus building therefore still a plausible ideological stance of canonizing films on digital networks like Facebook?

As observed in the interactions of online users in a Facebook group called Cinephiles!, one of the contentious issues was the almost invisible interface between the online user's agency (i.e. politics of canonization and cinephilia) and the algorithmic structure undermining this human agency. Like other social groups, members of Cinephiles! exercise their agency by raising their points of agreement and disagreements within the group's interactive space-all in the name of one's individual subjectivity. However, not all interactions are visible. Facebook's algorithmic structure retains its own mode of selection, privileging the more active thread over the less active thread. The positionality of choice in Facebook remains wedged within this dual layer of agency and technical apparatus, often disguised as pure human agency.

With this in mind, the following questions arise: If a network of incommensurable differences exist in web cinephilia, then on what level are the roles of social media, digital algorithms, and the information infrastructure complicit with these politics? With the retrofitting of Facebook algorithms, is the activity of selection still possible in the digital era?

With these questions in mind, this essay seeks to problematize cinephilia in the digital era through a historiographic encounter with Cinephiles!

\section{Early Periods}

As the moderator and founder of Cinephiles! for more than seven years now, I have been involved in almost all activities related to the group and often played multiple roles as content director, arbiter in discussion and debates, and main organizer of meet-ups and film screenings. Cinephiles! has become notorious for being a formidably active forum site of discoursecounter-discourse-and-debate on Philippine cinema in the early 2010s.

Despite its robust discursive culture, I cannot freely associate the cinephilia in Cinephiles! with the dominant American or European model of cinephilia that rely largely on a culture of movie-watching, which often involve film festival hopping. Cinephilia in Facebook, contrary to what Staiger (1985) discussed in Politics of Film Canons, is not necessarily conditioned by consensus, but rather by concentrations and dispersals controlled primarily by the agency-apparatus dialectic. 
Cinephiles! emerged last 5 November 2010 within the intersections of Facebook network interface of timelines, notes, and public and private exchanges. From a selection game among Filipino cinephiles-Jeffrey Deyto, Eduardo Dayao, Noel Vera, Jon Lazam and others-called "Fifteen films in Fifteen Minutes" where a Facebook user publishes a quick note after being tagged by another user on a note, I decided to create a group to collect these people in one place. Cinephiles! started with only seven members but quickly grew to hundreds of members in the first year and then to thousands of members in the next few years.

The tagging game was instrumental in shaping Cinephiles?'s first years of activities. In one Facebook note, I made a list of personal favorites dated 20 September 2010 (Mendizabal, 2010b). Looking at this list, which is subdivided in two categories: "a personal favourite from the heart" and an "alternative intellectual fifteen" one can see how web cinephilic activity diverges from what Jonathan Rosenbaum (2010) observed in cine clubs in France during the 1960s and 70s as written in the book Goodbye Cinema, Hello Cinephilia.

Web cinephilia, as seen from these activities, is no longer centered on an actualized social space of the theatre, but rather, on the online portal that acts as the site of after-screening discussion. The cascade-style and the commentary-centered design contributed to simulating the "communitylike" interaction of actual groups. The most active posts, or "the talk of the town," are usually found on top of the group timeline. The group is set to public, meaning other Facebook users who are not members of the group can see posts.

\section{In Search of a Collective Purpose}

I initially conceived the group without an ultimate purpose. I wanted the group to constitute its own subjectivity with minimal supervision. As administrator, I regulate posts and membership. The initial group description in 2010 is: "a group dedicated to Pinoy cinephiles" (Mendizabal, 2011b) with no clear description of a Pinoy cinephile. Much of the early periods comprised of activities of disclosure: levelling off, establishing ground, and determining one's positionality and opinion in a pool of like-minded people. In the early periods, film taste was usually a big topic of discussion, and listing films was a complementary activities (Morelos, 2010). The polemical nature of the group and its active discussions made it notorious to lurkers and anonymous users. Membership rose from seven to today's 7, 715.

In the early months of the group, several problems regarding Philippine cinema emerged in the discussions: digital piracy; media and film literacy: eroding stand-alone theatrical spaces: the rise of multiplex conglomerates 
like SM Supermall Cinemas and AyalaMalls Cinema that monopolize film distribution around the country; and the long-standing divide between indie cinema and mainstream cinema.

One of the first issues the group dealt with was diverging opinions between two sets of people: those who justify piracy as a democratizing apparatus and those who believe that piracy is theft and a form of copyright infringement.

Cinephiles! is not entirely composed of cinephiles with purely cinephilic sensibilities. Some members are also film studio executives. In one post, a user was looking for a copy of Sherad Anthony Sanchez's Imburnal (2008). An industry executive flagged some users for spreading a copy of Imburnal among members of Cinephiles! When a member requested for a copy of the film (cf. Labastilla, 2011), the request sparked a heated private debate among group members including industry executives about the source of the pirated copy of Imburnal (2008). The copy that circulated among members was only a copy of the original rip version. The original version remains untraceable.

The question of digital piracy continued in recent discussions and became one of the group's formidable problemtiques (e.g., Lavina, 2014; Sio, 2014). During the group's sixth year, piracy remained a focal subject with the issue surrounding leaked copies of the film Achy Breaky Hearts (2016) (cf. Cielo, 2016).

File sharing pirated copies of art films became one of the group's distinctive activities. Members resorted to piracy due to the lack of legitimate distribution networks of foreign art films in Philippine film culture. Usually sourced through exclusive torrent sites and sometimes through peer-topeer file transfer, the files spread among members of the group and were usually stored on private hard drives. Such practice is also made possible by the digital networks' homogenized technological infrastructure that allows massive transfer of files from one server computer to another in a span of one minute to an hour.

In Cinephiles!', digital piracy was also a hierarchizing parameter. One's ascendancy was determined by how many films you watched and their rarity or web accessibility. Members with access to private torrent sites also have greater access to little-viewed films than those who can only access public torrent sites.

Cinephiles! had been maintaining a piracy thread (cf. Deyto, 2012), as early as 14 November 2011 (e.g., Ajero, 2011). The piracy thread is a contentious illicit space providing critical information about films illegally circulated online. Members anticipate additions to the list of leaked files. The thread performed a double function: it disclosed the event of leakage 
by flagging and advertising titles without revealing the source of the leak. The thread was a monitoring sheet for recently released foreign films and a few of the local films.

The intervention of industry players also changed the way the group interacted on the piracy threads; members avoided being flagged or policed by industry executives and lurking authorities. This self-imposed rule inculcated panopticized group behaviour. Due to the public status of the group, members were vulnerable to surveillance and scrutiny.

With public interest came public criticism of the hive mentality and culture of ostracization. One particular instance was Rolando Tolentino's review of Ang Nawawala titled "Burgis na Juvenalia" (Tolentino, 2012). It triggered a heated online debate. Tolentino claimed the film lacked reflexivity and socio-political significance. In a response, Vincenzo Tagle (2012) argued that "[not] all movies have to be a commentary on the sociopolitical status of the country." Debates in the group are never resolved. Most, if not all, are left open-ended without reflection or action. The hive locale of the group only concentrates the discourse and debates within its online boundaries.

However, on several occasion, the group also participated in collective action. After one year of its inception the group refurbished a purposive and politicized collective subjectivity highlighted in its three specific goals, "to promote Philippine Cinema to the Filipino audience and the world; to further the discourse on film criticism and film writing; to discuss issues in filmmaking, film reception, and film distribution" (Mendizabal, 2011c).

This newly found collective subjectivity resulted in a series of online and offline activities, which transformed the group into a partially organized entity committed to finding alternative voices in Philippine cinema. One of its fruitful activities was the first anniversary group party that launched an atypical film screening (Mendizabal, 2011d) and a new way of selecting films for successive anniversary screenings. In a game adapted from a MUBI Forum post, members were asked to suggest one film per person. Of this selection, members add two points to their favourite films and subtract a point each for two of their least favourite films (Mendizabal, 2011a). After numerous iterations, scores were tallied and one film emerged as the winner of the game.

The group meet-ups, anniversaries, and screenings were often organized with a Manila-based audience in mind. It was counter-intuitive to conduct meet-ups; as a digital group forum, online meet-ups would have fostered a more inclusive experience for non-Manila-based members. However: meeting potentially created a space where the community formalized social organization outside the online realm. Indeed, these occasional meet-ups provided a tangible collective subjectivity. 
This collective corporeality of the group actualized several advocacy projects, the most notable being the signature campaign for Emerson Reyes's disqualification case in Cinemalaya Film Festival 2012 (cf. Marinque, 2012; Arbogena, 2012; Online petition launched over Cinemalaya controversy, 2012). In another instance, the group conducted a donation drive for the victims of Typhoon Yolanda in 2013 (Mendizabal, 2013). These efforts could not be taken as simple gestures of gratitude; instead, these activities should be seen as primarily driven by a communal desire to raise the ethical stakes of the group's online existence.

\section{A Question of Legitimacy: Towards the Idea of Post-Zine}

Conversations within the group underscore questions about its legitimacy both as a space for discourse on Philippine Cinema, as a new critics group. The group pushed for a renewed vigour in problematizing Philippine cinema outside the collegial and institutional bodies of organization, and a polemical culture of criticism accommodating and re-circulating various subjectivities and geopolitical positions. Ira Lastrilla (2011) questioned the polemic culture in the group's early years: "if the concentration of Filipino cinephiles on this page reaches a particular level, do we think we have the capability to make a Film Magazine (a la Lumen and Rouge)? or rather should we create a Film Magazine?" (Lastrilla, 2011, para. 1).

Indeed, in the group's historical trajectory from the early to mid 2010s, there is a recurring collective dream, albeit vocalized only by a few people, of curating a legitimate online or print film magazine. Early efforts to derive a legitimate and formalized mode of discourse of the group occurred during the creation of the blogathon site Cinematon! Cinematon! (Mendizabal, 2010a) formed concurrently with Cinephiles!. Cinematon! Cinematon!, a precursor to Cinephiles!, was formed between embassy screenings at EDSA Shangri-la mall in September 2010. The group emerged in the following circumstance: "On [sic] a group discussion over coffee last September 17, 2010 at Cine Europa 13, the group [Fidel Antonio Medel, SanrielAjero, EpoyDeyto and me] felt the need to go against the traditional trend in film criticism" (Mendizabal, 2010a). Cinematon! Cinematon! initially broke away from traditional film criticism. The term "traditional film criticism" still draws problematic conceptual assertions. Members of Cinematon! Cinematon! eventually formed Cinephiles!

A year after Cinematon! Cinematon!, the Indiocine: A Journal on Philippine Cinema was published as a response to Lastrilla's (2011) call for a magazine. It was launched during the group's first anniversary on 11 November 2011 with the hope of creating "a bilingual, independent, pluralist, non-profit journal [...] on Philippine Cinema [that is not] affiliated 
[with] any institutions, [and] can be freely accessed online" (Mendizabal, 2011d). Indiocine's two issues were ambitious attempts at a formal and traditional magazine.

One of the hurdles of online magazine publishing was the failure to formally constitute an editorial team capable of dedicating an ample amount of time, effort, and financial capital to write and fund an issue. The group's occasional anti-intellectualism and lukewarm reception to long form film criticism and in-depth analysis were also challenges the group had to overcome. For many members, a film journal was an academic project and, as far as their subject positions are concerned, academizing film discourse is an end in itself, a closure of filmic discourse. Few were willing to engage with academic jargon and in-depth long form film criticism.

In 2011, after Indiocine, the group built on its cinephilic cultural capital after being awarded free use of theatrical space at the UP Film Center Videotheque once a month. These underground screenings ran from November 2012 to November 2015. Each screening featured a curated list of rare films not often screened in other local theaters. The time and space offered by the UP Film Center also provided a chance for Manila-based members to discuss timely issues in Philippine cinema. Though screening ended in 2015 due to repairs, the group remained active online.

Failure to sustain a print film magazine occasioned new paradigms and spaces for film discussion. The digital convergence of the media homogenizes material space and time, repositions and "deterritorializes" what was once niche. Print magazines address a niche, a compartmentalized assemblage of one hybrid topic of interest i.e. fashion, fitness, bodybuilding, show business, etc. Cinephiles! lacks a niche-like environment and the political economy that regulates the content, design, editing, distribution, and marketability of the traditional magazine.

Indeed, what constitutes Cinephiles! as post-zine is its attempt to reify its own political economy outside the regulatory framework of traditional magazines. The algorithmic intervention of Facebook also contributes to its post-zine condition. If traditional niche magazines require a bureaucratic structure to approve content, content on Facebook is selected by an artificial algorithmic entity that monitors one's daily activities online. A group's clicklike-share-react-comment sociality does not assure the administrator's full control over content on the Facebook group timeline. Post-zine condition privileges computational logic that controls the production and reproduction of digital content. The editorial power disassembles as soon as the computational infrastructure of Facebook assimilates content within its algorithmic machine. What remains in the group timeline is pre-analyzed and pre-sorted content. Spam posts and obscene content are instantly removed, while a thematized code arranges posts based on preference. 
If post-zine conditions result from non-traditional dynamics of digital interfaces, then traditional forms of media may take a new form. Nichebuilding in magazines requires not only content but also correctly packaged, aesthetically appealing, well-designed content capable of transmitting affective experiences. The individualized and atomized audience of the social media is not neither a magazine reader nor a consumer that fits any niche at all. The Facebook user loses its own organic agency as soon one's content is metabolized by the Facebook algorithm.

\section{From Post-Zine to Post-Cinephilia}

I opened this essay by highlighting the implications of Janet Staiger's 1985 essay on film canons on the politics of cinephilia. The question of film canons usually arises alongside the activity of cinephilia. Cinephiles! actively questioned what constituted a film canon Filipinos can recognize as our own. Beyond the canon-cinephilia relation, Staiger's essay highlighted the importance of examining the positionality of the politics of choice in a network of power relations. Though Facebook follows an algorithm-driven presentational logic in curating group timelines, Cinephiles! surpassed its mere existence as an online forum. It formed a social corpus driven to make a mark on contemporary Philippine cinema.

Cinephiles! as post-zine challenges the formally recognized institutional form of the magazine. Its post-zine condition can also be attributed to the diminishing power of institutional practice of writing and the rise of algorithmic-controlled digital content that posture in the digital media interface as non-writing, and as a sign system devoid of agency. The rise of online forums on cinema in recent years also inaugurates a new form of cinephilia. Cinephiles! as a group was a marker for this transition in local film culture. An in-depth analysis of its internal structure would yield a more nuanced understanding of the deterritorialization of signs, the dissolution of the original referent, and the massive digitization of culture. Migration towards digital media could render vanguards of knowledge-and culturalproduction processes obsolete. What lies in the post-Cinephiles! era is the establishment of digital communities completely devoid of social agency. Can this be the sign of the emergence of what Deleuze called a "society of control"? Is Cinephiles! symptomatic of the arrival of a society of control? Cinephiles! like other online forums prior and concurrent to its existence proved to be a significant moment in Philippine film culture during the early 2010 s. 


\section{References}

Online petition launched over Cinemalaya controversy. (2012). ABS-CBN News. Retrieved from http:// news.abs-cbn.com/lifestyle/03/05/12/online-petition-launched-over-cinemalaya-controversy

Ajero, S.C. [Sanriel Chris]. (2011, November 14). Since busy kayo lahatsa film festivals around, bakanaoverlook niyo latest online leaks from last week. I Wish (Kiseki) - Koreeda, 2011, The Day He Arrives - Hong, 2011 (no subs yet), Elena - Zvyagintsev, 2011, Restless - van Sant, 2011, Texas Killing Fields - Ami Mann, 2011, Like Crazy - Doremus, 2011 (screener), A Dangerous Method - Cronenberg, 2011 (cam), Download awaaaay! [Facebook Group Post]. Retrieved from https://web.facebook.com/ groups/pinoycinephiles/permalink/299623650057020/?match=bGVha2VkLGxIYWtzLGxIYWs\%3D (10).

Cielo, C.R. [Carlo Rollbackthetuition]. (2015, July 6). Norman Wilwayco, July 6, 2016, Kawawanaman kayo baka ten times a day nalang kayo makakainniyan! Nagwawalaangmga mainstream direktor/artistadahilumanosapamimiratangmga peeps ngpelikulanila at pag-share ngmga shit nilasafacebook. Milyon-milyon daw angnawawalasa Star Cinema at iba pang naglalakihang studio dahil sa pambuburaot ng mga pirata. Dikomaiwasanghindimagsalitatungkolditosa shit na 'to. [Facebook Group Post]. Retrieved from https://www.facebook.com/groups/pinoycinephiles/perm alink/1214077748611601/?match=cGlyYXRh (8).

Deyto, E. [Epoy] (2012, June 8). (dahil halos dalawangtaonna at di pa rinmahanapang pirate-update thread), itonaang official pirate-update thread. Post the freshest leaks here. [Facebook Group Post]. Retrieved from https://www.facebook.com/groups/pinoycinephiles/search/?query=pirate\%20 update\%20thread (9).

Lavina, J. [John]. (2014, November 9).i want your side about piracy. do you buy pirated DVDs? if yes, bakit? are you aware that its a crime? satinginnyo, bakitbatinatangkilikngmga Pilipino ang Pirated DVDs? [Facebook Group Post]. Retrieved from https://www.facebook.com/groups/pinoycinephiles/perm alink/868727723146607/?match=cGlyYWN5 (6).

Labastilla, S. [Skilty]. (2011, May 6). Hello cinephiles, would anyone here know where i can get a copy of sheradsanchez'simburnal? thanks! [Facebook Group Post]. Retrieved from https://www.facebook. com/groups/pinoycinephiles/permalink/212233612129358/?match=aW1idXJuYWw\%3D (5).

Lastrilla, I. [Ira] (2011, April 24). if the concentration of Filipino cinephiles on this page reaches a particular level, do we think we have the capability to make a Film Magazine (a la Lumen and Rouge)? or rather should we create a Film Magazine? [Facebook Group Post]. Retrieved from https://www. facebook.com/groups/pinoycinephiles/permalink/209289945757058/?match=Y2luZXBoaWxlcyxj cmVhdGluZyxjcmVhdGU\%3D (19).

Mendizabal, A. D. [Adrian Dollente]. (2010a). Cinematon! Cinematon! Cinematon! Cinematon! Retrieved from http://cinematoncinematon.blogspot.com/2010/10/cinematon-filipinas.html (21).

Mendizabal, A. D. [Adrian Dollente]. (2010b, September 21). 15 Films in 15 Minutes [Facebook Note]. Retrieved from https://web.facebook.com/notes/adrian-dollente-mendizabal/15-films-in-15minutes $/ 148853258486754 /$ ?comment_id=1466573083381425\&ref=notif\&notif_t $=$ note_ comment\&notif_id=1493343172496379\&_rdc=1\&_rdr (1).

Mendizabal, A. D. [Adrian Dollente]. (2010c, November 26) Guys! CINEMATON! CINEMATON! is still on going! Visit our site! WEEE! [Facebook Group Link Post]. Retrieved from https://web.facebook.com/ 
groups/pinoycinephiles/permalink/171516456201074/?match=Y2luZW1hdG9ulGNpbmVtYXRvbi xjaW5lbWF0b24\%3D (20).

Mendizabal, A. D. [Adrian Dollente]. (2011a, October 27).VOTING POLL FOR CINEPHILES ANNIV!!! The first eleven mems has finally chosen eleven films to be voted upon by fellow members of cinephiles to be shown this coming November 19 or 20 at CINEPHILES ANNIV PARTY. [Facebook Group Post]. Retrieved from https://www.facebook.com/groups/pinoycinephiles/ permalink/2910569842470 20/?match=Y2luZXBoaWxIcyBhbm5pdixjaW5IcGhpbGVzLGNpbmVwaGlsZSxhbm5pdg\%3D\%3D (15).

Mendizabal, A. D. [Adrian Dollente]. (2011b, November 5). About: Founded last Nov 5, 2010, the group is created for Filipino film enthusiasts. [Facebook Page Profile]. Retrieved from https://www.facebook. com/pg/Cinephiles-169778119781779/about/?ref=page_internal.

Mendizabal, A. D. [Adrian Dollente]. (2011c, November 5). Mission: to promote Philippine Cinema to the Filipino audience and the world, to further the discourse on film criticism and film writing. to discuss issues in filmmaking, film reception, distribution. [Facebook Page Profile]. Retrieved from https://www.facebook.com/pg/Cinephiles-169778119781779/about/?ref=page_internal (13).

Mendizabal, A. D. [Adrian Dollente]. (2011d, November 11) About. [Facebook Page Profile]. Retrieved from https://www.facebook.com/pg/Indiocine/about/?ref=page_internal (22).

Mendizabal, A. D. [Adrian Dollente] (2011e, November 24). ATTN:You're all invited for our first anniversary gathering. Here's the schedule of activities: 5PM - 6PM: Registration 6PM - 7PM: Short Opening Program > Welcome Remarks + Cinephiles. [Facebook Group Page Post]. Retrieved from https:// www.facebook.com/groups/pinoycinephiles/permalink/299404453412273/?match=YW5uaXZIcn NhcnksY2luZXBoaWxlcyxzY3JIZW5pbmc\%3D (14).

Mendizabal, A. D. [Adrian Dollente]. (2013, November 14). Good day CINEPHILES! We're doing this on November 23 (Saturday) as an alternative to our CINEPHILES ANNIVERSARY PARTY. It will be a twofold event: CINEMALIBRE FILM SCREENING. [Facebook Group Post]. Retrieved from https://www. facebook.com/groups/pinoycinephiles/permalink/684844561534925/?match=Y2luZXBoaWxlcyB hbm5pdmVyc2FyeSxhbm5pdmVyc2FyeSxjaW5lcGhpbGVzLHNjcmVlbmluZw\%3D\%3D (18).

Montañano, J. R. [Joyce Rochelle]. (2011, February 21). May kopyana 'kong "Imburnal". Excited na 'kongpanoorin, kasowala pang time. [Facebook Group Post]. Retrieved from https://www.facebook. com/groups/pinoycinephiles/permalink/194000197286033/?match=aW1idXJuYWw\%3Dhttps:// web.facebook.com/groups/pinoycinephiles/permalink/194000197286033/?match=aW1idXJuYW w\%3D\&_rdc=1\&_rdr (4).

Morelos, R. A. [Renelson Antonius]. (2010, November 9). 15 Asian Film Picks. (Note:This is in response to Chris' earlier post. I assume that this would still follow the 15-minute timeframe. For my own reasons, I won't include films from our own country. [Facebook Group Post]. Retrieved from https:// www.facebook.com/groups/pinoycinephiles/permalink/167374049948648/?match=aW4gcmVzc G9uc2UscmVzcG9uc2U\%3D (3).

Rosenbaum, J. (2010). Goodbye cinema, hello cinephilia: film culture in transition. Chicago and London:The University of Chicago Press.

Sio, A. [Ar]. (2014, December 8). [Serious] What is this group's policy regarding copyright infringement? I recall seeing so many members going on tirades when Cinemalaya uploaded entries from previous years on its YouTube channel, and yet no one bats an eyelash when someone starts a "pirate thread" 
here. [Facebook Group Post]. Retrieved from https://www.facebook.com/groups/pinoycinephiles/ permalink/883876654965047/?match=cGlyYWN5LHBpcmF0ZQ\%3D\%3D (7).

Staiger, J. (1985). The politics of film canons. Cinema Journal, 24(3), 4. doi: 10.2307/1225428

Tagle, V. [Vincenzo]. (2012, August 10). A response to 'BurgisnaJuvenilia', or a defense of 'AngNawawala'. [Blog Entry]. Retrieved from http://webcache.googleusercontent.com/search?q=cache:ViNG3hO UrOAJ:https://wetalkaboutmovies.wordpress.com/2012/08/10/a-response-to-burgis-na-juveniliaor-a-defense-of-ang-nawawala/\&num $=1 \& \mathrm{hl}=\mathrm{en} \& \mathrm{gl}=\mathrm{ph} \&$ strip $=0 \& v w s r c=0$ (12).

Tolentino, R. [Rolando]. (2012, August 7). Burgisna juvenilia. Ayon kay Bienvenido Lumbera, huradong Cinemalaya 2012, ang isang tampok sa mga lahok ay ang pagtalakay ng isa na namang aspektong buhay sa lipunang Filipino: ang nakakataas na uri't may kaya. Hindi ko alam kung good news bad PINOYWEEKLY.ORG. [Facebook Group Link Post]. Retrieved from https://www.facebook.com/ groups/pinoycinephiles/permalink/470501792969204/?match=cm9sYW5kbyB0b2xlbnRpbm8sd G9sZW50aW5vLHJvbGFuZG8s (11).

ADRIAN D. MENDIZABAL is a MA Media Studies (Film) student of the University of the Philippines Film Institute (UPFI). He has contributed essays on Philippine cinema to NANG Magazine, Kino Punch, La Furia Umana, New Durian Cinema, Transit Journal, Sinekultura Film Journal, and MUBI Notebook. He is currently working on a research project exploring the relationship of time and Lav Diaz's cinema. He is also the Philippine delegate and blog editor of Cinema and Moving Image Research Assembly (CAMIRA). His main interest is film-philosophy (corresponding author:adrian.lessegers@gmail.com). 
